\title{
Importance of damage data from destructive earthquakes for seismic microzoning Damage distribution during the 1923 Kanto, Japan, earthquake
}

\author{
Saburoh Midorikawa \\ Department of Built Environment, Tokyo Institute of Technology, Yokohama, Japan
}

\begin{abstract}
To verify the results of seismic microzoning and to improve techniques, the damage data of past destructive earthquakes is an important key reference. The damage data of the 1923 Kanto, Japan, earthquake in the epicentral region are collected and compiled to produce the most reliable and detailed damage map. The damage map is compared with the results from the existing damage assessment and is used to discuss revision of the site amplification evaluation.
\end{abstract}

Key words seismic microzoning - damage datathe 1923 Kanto earthquake - Japan

\section{Introduction}

Seismic microzoning has been conducted as the basis for earthquake disaster mitigation planning. Earthquake ground motions are directly related to the seismic force acting on structures and to geotechnical hazards such as liquefaction and slope failure. Therefore, zoning for ground motion is an essential part of seismic microzoning. Many approaches for ground motion zoning have been proposed such as:

1) Damage survey of destructive earthquakes.

Mailing address: Prof. Saburoh Midorikawa, Department of Built Environment, Tokyo Institute of Technology, 4259 Nagatsuta, Midori-ku, Yokohama 226-8502, Japan; e-mail: smidorik@enveng.titech.ac.jp
2) Questionnaire seismic intensity survey of local earthquakes.

3) Geological and geomorphological classification.

4) Microtremor analysis,

5) Ground response analysis.

In practice, appropriate methods for each area should be selected from these approaches since the available data vary from region to region (e.g., Technical Committee for Earthquake Geotechnical Engineering, TC4, ISSMGE, 1999).

The results obtained by zoning techniques are preferably verified with the observation data. Therefore, the damage survey of destructive earthquakes plays two important roles, such as: 1) conducting a zoning technique simply from the damage distribution, and 2) collection of material for verification of zoning results. Destructive earthquakes occur with low frequency even in high seismicity areas. As a result, it is important to collect, compile, and interpret the information from old or historical earth- 
quakes. This paper shows the importance of the damage data from destructive earthquakes for seismic microzoning through a case study of the 1923 Kanto earthquake in Japan.

\section{Importance of the $\mathbf{1 9 2 3}$ Kanto earthquake for zoning of the Tokyo Metropolitan area}

To produce the zoning map of Tokyo, Imamura (1913) compiled the damage data of the 1855 Tokyo earthquake ( $M$ 6.9) in which more than 7000 people were killed. From the damage map of the earthquake together with the old topographic map, he divided the city area into four zones such as low, medium, high and very high hazard zones, as shown in fig. 1. This map was the first microzoning map proposed in Japan. Ten years after his work, Tokyo was attacked

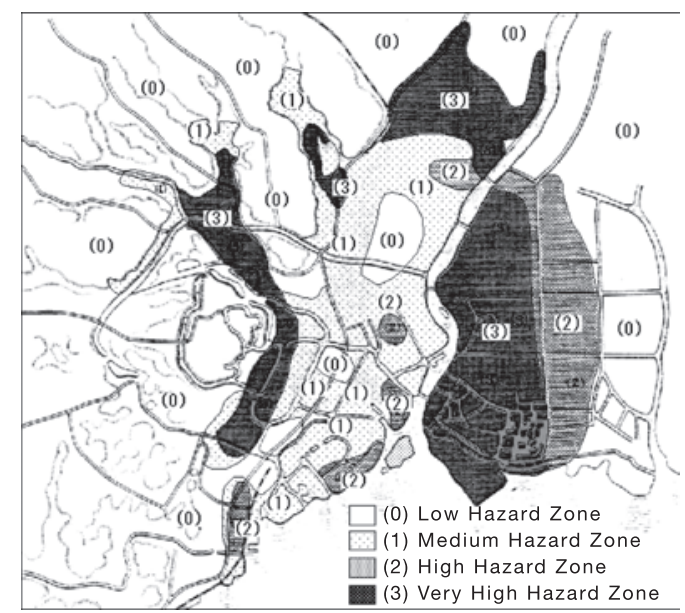

Fig. 1. Seismic microzoning map of Tokyo (Imamura, 1913).

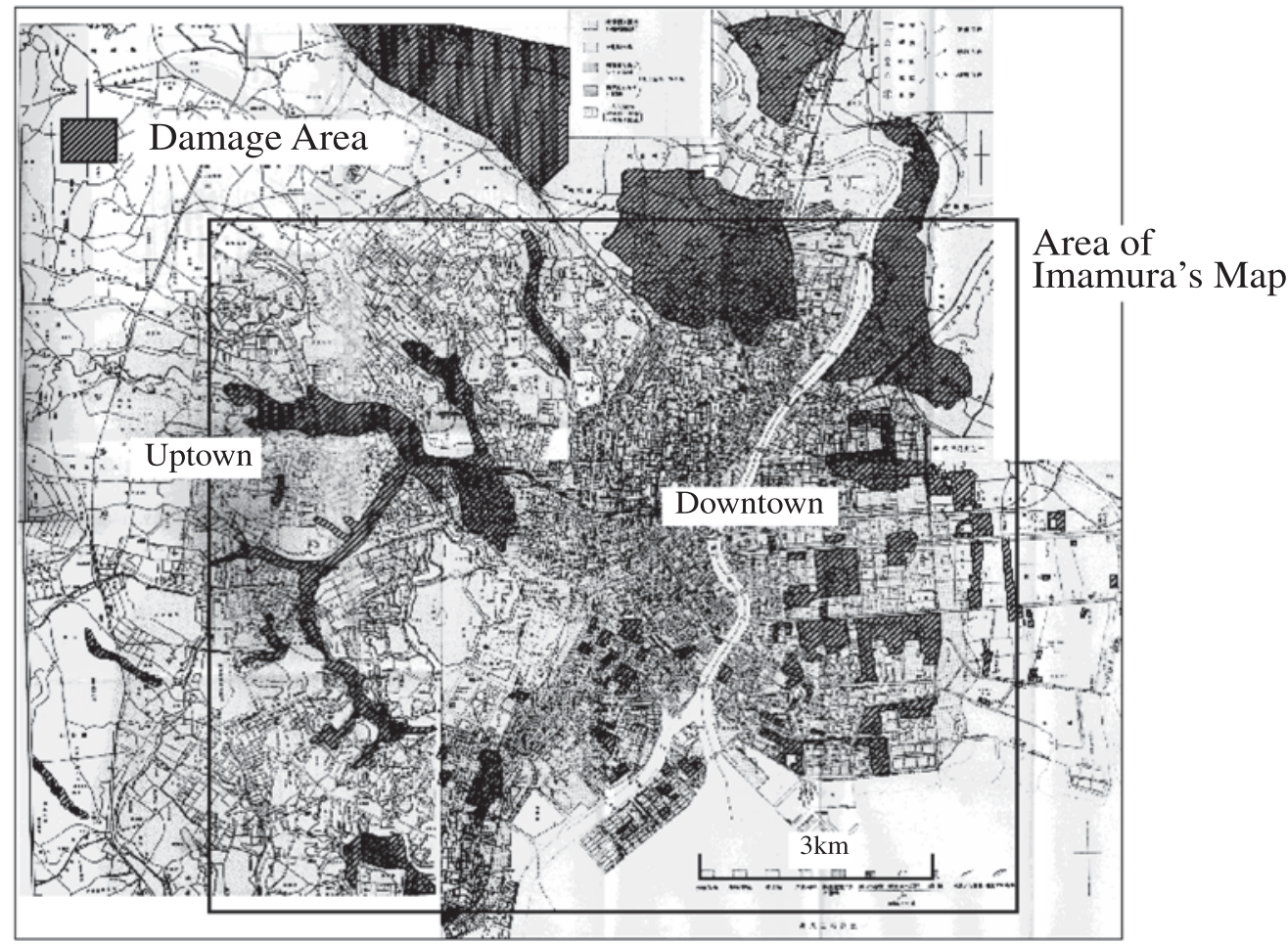

Fig. 2. Damage distribution in Tokyo during the 1923 Kanto earthquake (Geological Survey of Japan, 1925). 
again by the 1923 Kanto earthquake (M 7.9). The damage distribution of the Kanto earthquake was surveyed by the Geological Survey of Japan (1925a), as shown in fig. 2. As most of downtown of Tokyo was burned out by the earthquake fire, they may have overlooked some of the areas damaged by ground shaking. Considering the incompleteness of the damage map shown in fig. 2, the damage distribution of the Kanto earthquake is consistent with Imamura's zoning map and could be predicted by the Imamura's map. This demonstrates the effectiveness of the damage data of the past destructive earthquakes.

Now theTokyo Metropolitan area has grown to a huge densely populated area. The area consists of Tokyo, Kanagawa, Saitama and Chiba Prefectures, with a population of 27 million. The location of the area is shown in fig. 3. If Tokyo Metropolitan area is attacked again by the Kanto earthquake, the amount of the direct loss is estimated as more than two trillion dollars which is about 10 times of that of the 1995 Kobe earthquake (Risk Management Solutions, 1995). As shown by a square in fig. 3, the seismic microzoning map by Imamura (1913) covers only the central part of Tokyo Prefecture and is no longer proper to evaluate the seismic hazard in Tokyo Metropolitan area.

Since the 1923 Kanto earthquake was the last destructive event for Tokyo Metropolitan area, the damage data of the Kanto earthquake will provide the basic information for the seismic microzoning of the Tokyo Metropolitan area. Several reports on the damage to houses during the Kanto earthquake have been published, as described by Takemura and Moroi (2001a). Among them, the damage data compiled by Matsuzawa (1925) have often been referred. Matsuzawa's data are based on the reports from local governments as of a few weeks after the earthquake. In the most disastrous regions, the damage survey had not been completed by that time because of the aftermath of the disaster. Some of the reported data might be preliminary rough estimates, and furthermore there seem to have been some mistakes in the reported data. As a result, some parts of the data set do not seem reliable, as pointed out by Matsuzawa himself (Matsuzawa, 1925).
About two months after the earthquake, the Ministry of Domestic Affairs ordered the local governments to conduct a complete damage survey. Based on the damage investigation, the statistical damage data were published by the Ministry of Domestic Affairs (1926). The published statistical data, however, were not well defined. For some towns, the numbers of the damaged residential houses were described, but for the other towns, the numbers consisted of both residential and non-residential houses. Unfortunately, many of the original documents of the survey data of the disastrous regions were lost mainly due to fires during the Second World War.

The Geological Survey of Japan also conducted the damage investigation in Tokyo, Kanagawa, Chiba, Saitama, Yamanashi, Shizuoka, Ibaragi, Tochigi and Gunma Prefectures (Inoue, 1925). Locations of these prefectures and the source area of the Kanto earthquake are shown in fig. 3. They published the reports on the damage in Tokyo, Chiba, Saitama, Ibaragi, Tochigi and Gunma Prefectures (Geological Survey of Japan, 1925a,b). The reports describe the damage for each sub-division of the towns and villages. From the descriptions, the detailed

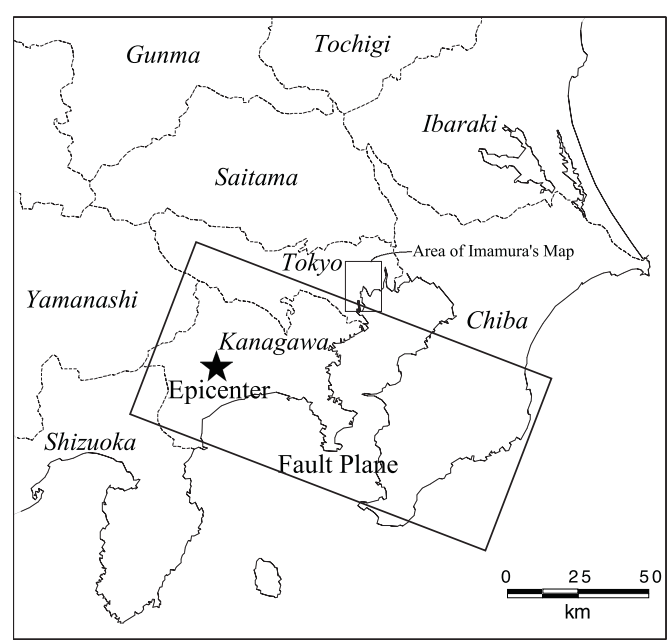

Fig. 3. Locations of epicenter and fault plane of the 1923 Kanto earthquake. 
intensity maps of Tokyo, Chiba, and Saitama Prefectures are derived and the effects of surface as reported by Moroi and Takemura (2001) and Takemura and Moroi (2001b,c,d).

Unfortunately, the reports on the damage in Kanagawa, Yamanashi and Shizuoka Prefectures were not published probably due to financial problems at the time of the earthquake. Among these three prefectures, Kanagawa Prefecture is located just on the epicentral area of the earthquake as shown in fig. 3 and suffered the most disastrous damage. As mentioned earlier, some of the statistical damage data for Kanagawa Prefecture have been published, but the reliability of these data has not been fully examined, so that the damage distribution of Kanagawa Prefecture is still unclear.

\section{Damage distribution of wooden houses in Kanagawa Prefecture}

In order to reveal the accurate damage distribution in Kanagawa Prefecture, three data set by Nishisaka (1924), Kanagawa Prefecture (1927) and the Agricultural Association of Kanagawa Prefecture (1925), in addition to the statistical damage data by Matsuzawa (1925) and the Ministry of Domestic Affairs (1926) mentioned earlier, were collected from local institutes for compilation of historical material (Shinbo and Midorikawa, 2001). As a result of examination of the five groups of data, the data of the Agricultural Association of Kanagawa Prefecture (1925) seem most reliable. The data have not been referred by the previous studies on the damage of the Kanto earthquake because that the Agricultural Association of Kanagawa Prefecture was a local organization whose reports were not noticed by engineering communities.

The data compiled by the Agricultural Association of Kanagawa Prefecture (1925) are the numbers of the damaged residential houses for each village and town. Since the major industry in Kanagawa Prefecture was agriculture at that time, the Agricultural Association of Kanagawa Prefecture was strongly related to the local governments. The data might be based on the original data of the damage survey as ordered by the Ministry of Domestic Affairs.
The distribution of the ratio of the collapsed houses based on the Agricultural Association of Kanagawa Prefecture (1925) is shown in fig. 4. Since the data for the urban areas such as Yokohama and Yokosuka cities are not included in the data of the Agricultural Association of Kanagawa Prefecture (1925), the supplementary data (Takahama et al., 2001; Committee for Publication of Yokosuka City Earthquake Disaster Report, 1932) are also used to draw the damage distribution. The damage distribution based on the data by Matsuzawa (1925) which have often been referred to, is also shown in fig. 5 .

In comparison with the damage map by Matsuzawa (1925), the damage tends to be smaller as shown in fig. 4 . This is mainly because the data by Matsuzawa include the damage to both residential and non-residential houses and the damage ratio was calculated dividing the number of damaged houses by the number of households which is equivalent to the number of residential houses.

As shown in the geological map of Kanagawa Prefecture (see fig. 6), the damage seems to be larger on alluvial deposits, suggesting local site effects. In particular, in most towns and villages on alluvial deposits along the Sagami River, the collapsed ratios are higher than $50 \%$.

The earthquake damage assessment has been conducted by Kanagawa Prefecture. Figure 7 shows the Japanese-scale seismic intensity map calculated for the Kanto earthquake by Kanagawa Prefecture (1999). The map is calculated by the empirical attenuation relationship of ground motion intensity and the site amplification evaluation technique based on the geological and geomorphological classification. To verify the calculated intensity map with the observed damage map, the correlation between the intensity and the damage ratio is necessary. Although there are uncertainties between the intensity scale and the damage ratio, a recent study suggests that the intensities 6 and 7 correspond to the collapsed ratios higher than $1 \%$ and 50 to $80 \%$, respectively (Nobata and Midorikawa, 2002). If the collapsed ratios higher than $1 \%, 10 \%$, and $50 \%$ are assumed to correspond to the intensities $6-, 6+$, and 7 , respectively, the calculated intensity map seems to be consistent with the observed damage map 


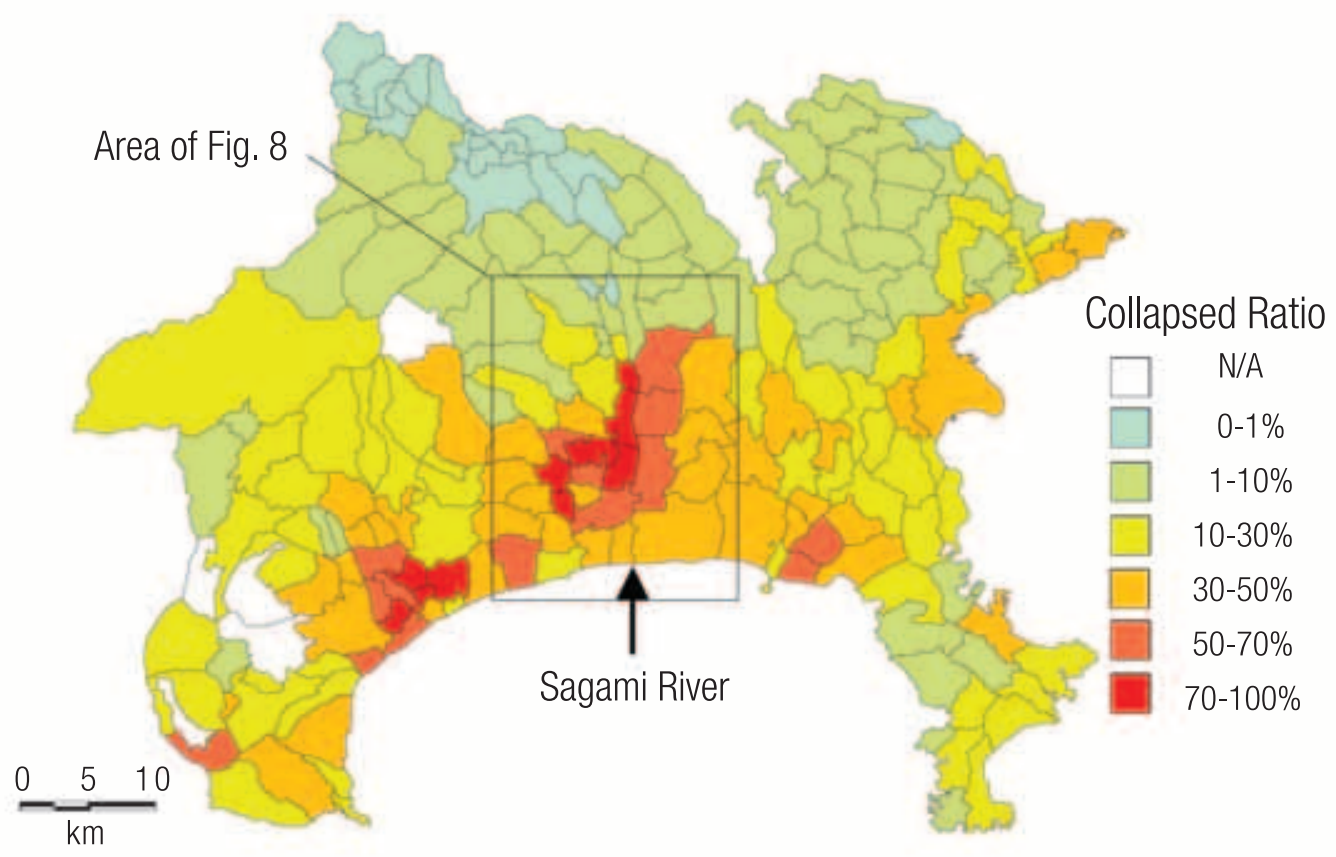

Fig. 4. The damage distribution of wooden houses in Kanagawa Prefecture by this study.

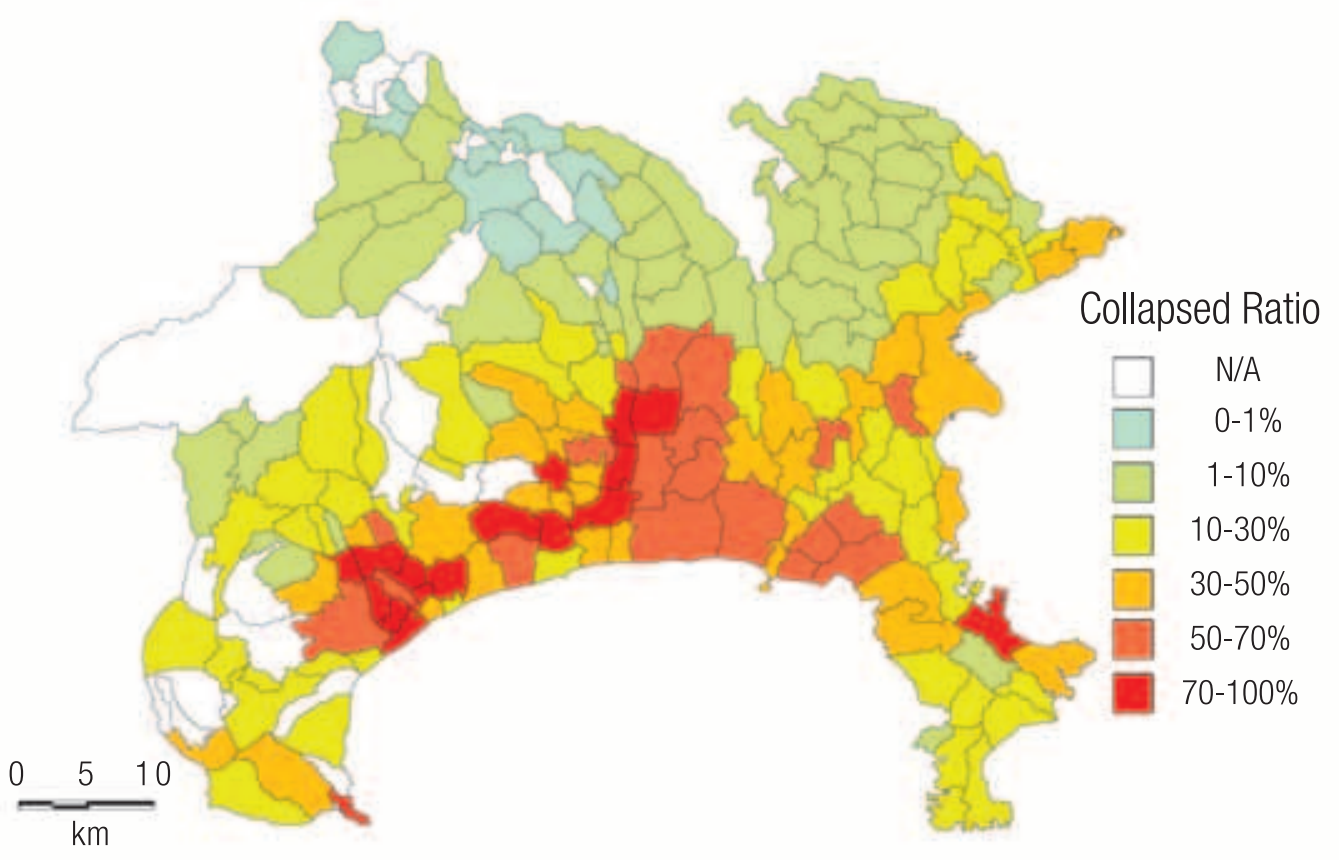

Fig. 5. The damage distribution of wooden houses in Kanagawa Prefecture by Matsuzawa (1925). 


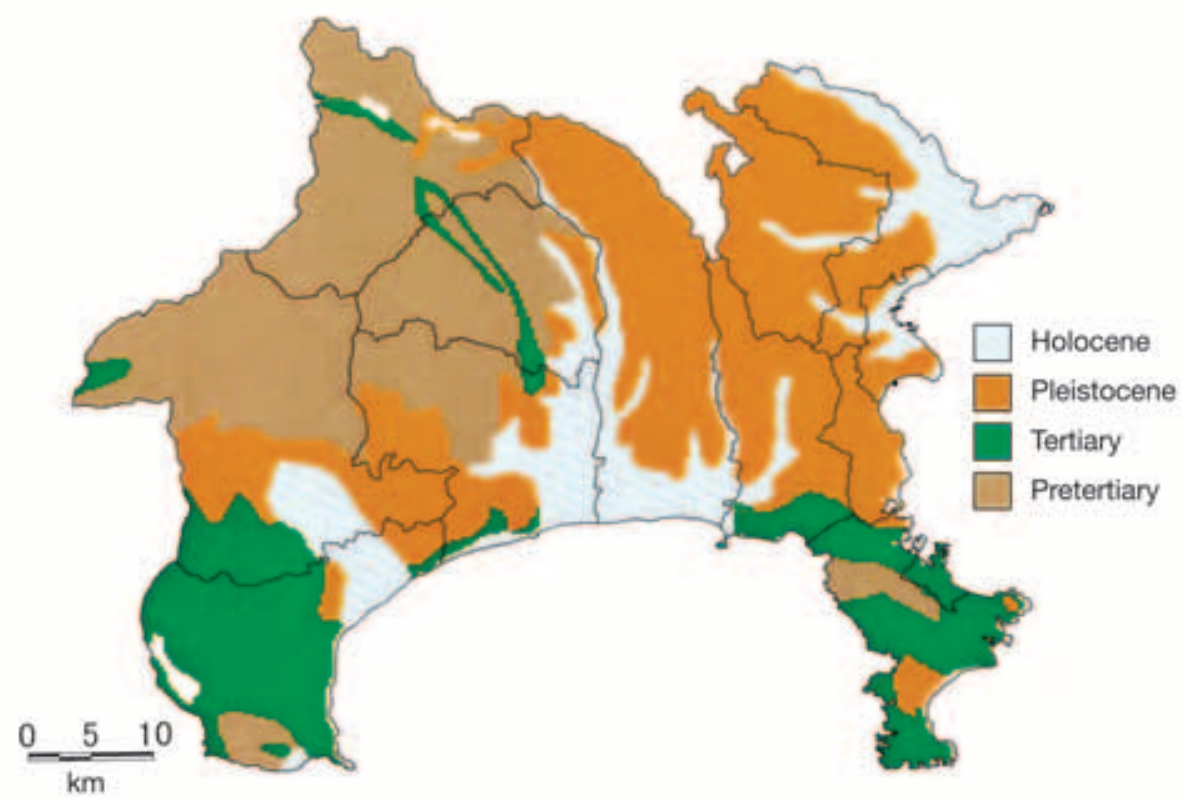

Fig. 6. Geological map of Kanagawa Prefecture.

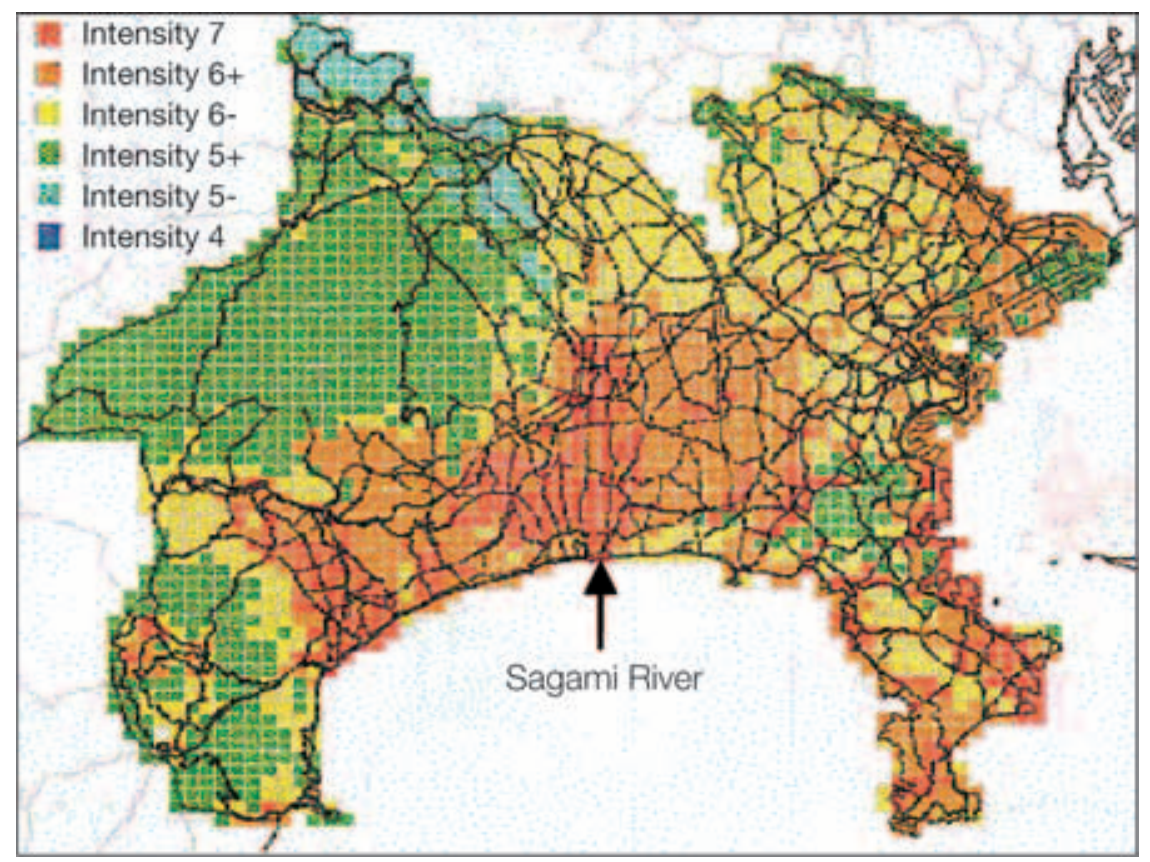

Fig. 7. Calculated seismic intensity map for the Kanto earthquake (Kanagawa Prefecture, 1999) 


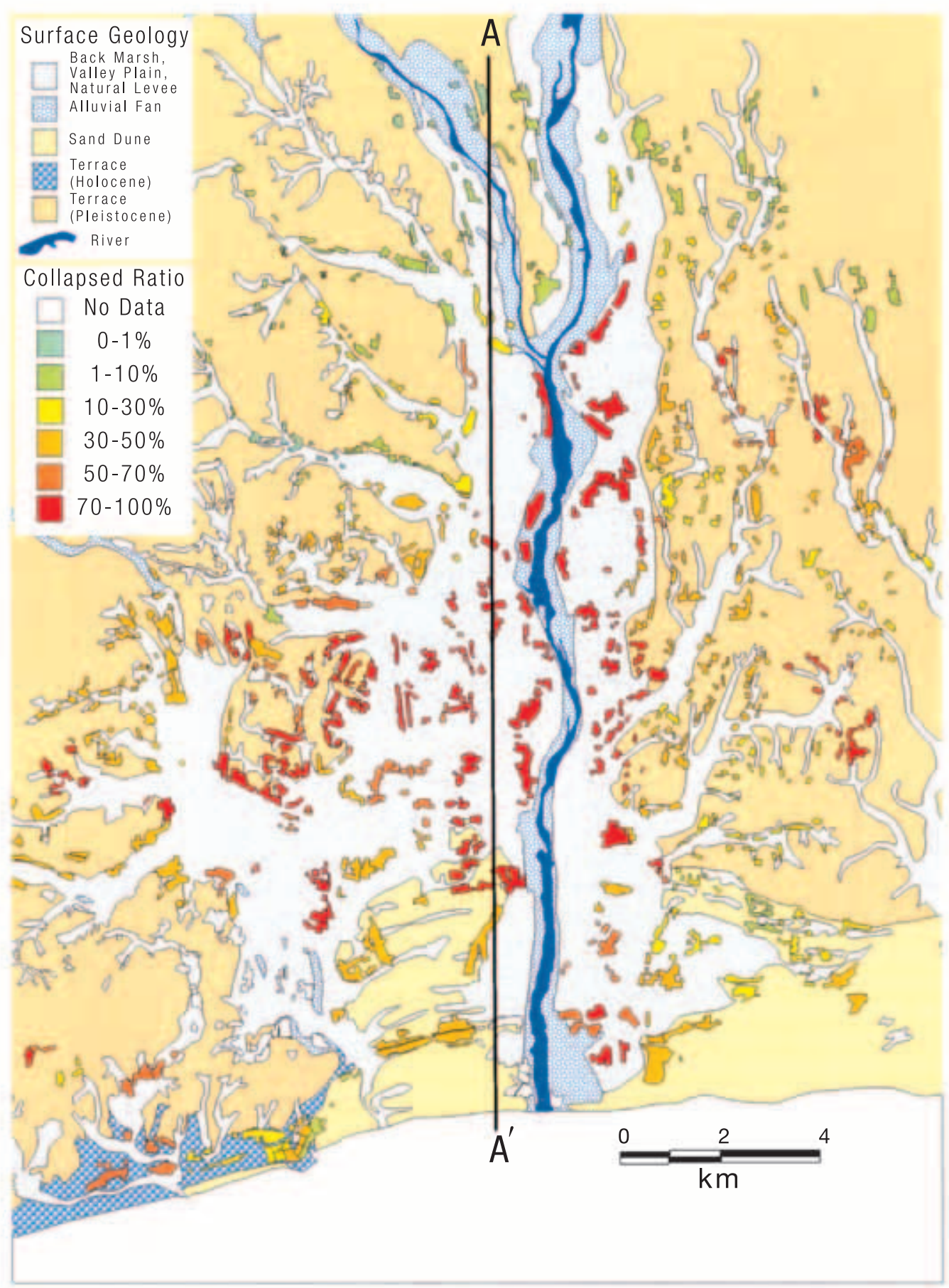

Fig. 8. Detailed damage distribution and geomorphological conditions along the Sagami River. 
in a broad sense, but in a more strict sense some discrepancies are found between both maps.

For example, in the area along the Sagami River, the observed damage is highest 5 to 15 $\mathrm{km}$ north from the coast and lower near the coast. The calculated intensity is highest from the coast to the north for a length of about $15 \mathrm{~km}$. The calculated high intensity zone seems to shift to the south in comparison with the observed damage zone. As the source of the earthquake is beneath the area as shown in fig. 3, this discrepancy may be related to the site amplification evaluation.

\section{Local site effects on the damage distribution}

In order to discuss the local site effects, the detailed damage distribution was investigated in the area along the Sagami River where heavy damage was observed. The area of investigation is shown by a square in fig. 4. More than 100 data sources such as the reports on local history or folklore, administrative documents, and the booklets of school anniversaries were collected. The data were interpreted and used to determine the ratio of collapsed houses at each section of towns or villages. Figure 8 shows the detailed distribution of the collapsed ratios. In the figure, the geomorphological conditions are overlaid. The correlation between the damage ratio and the geomorphological condition can be found; the collapsed ratios tend to be more than $70 \%$ at back marsh, valley plain, natural levee and alluvial fan, and less than $50 \%$ at sand dune and terrace.

Figure 9 shows the collapsed ratios at different geomorphological conditions. Although there is a large variation of the collapsed ratios in the same geomorphological classification, the average collapsed ratios are about $60 \%$ and $30 \%$ at lowland except sand dune and at sand dune and terrace, respectively. This suggests that the site amplification is smaller at sand dune and terrace. According to the previous studies (e.g., Matsuoka and Midorikawa, 1995), however, the site amplification has generally been considered to be larger at lowland including sand dune than at terrace.

Figure 10 shows the soil profile along the Sagami River (Kanagawa Prefecture, 1985) together with the collapsed ratio. Lateral variations of the soil profiles perpendicular to the

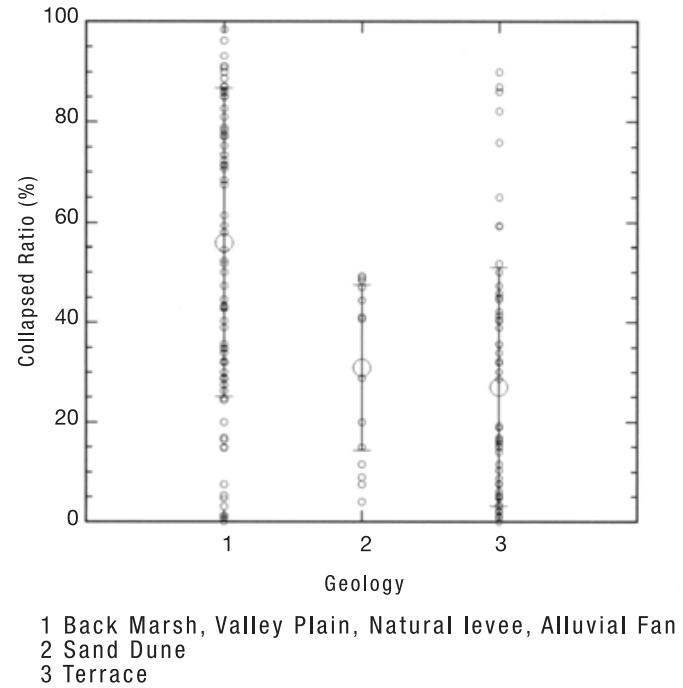

Fig. 9. Collapsed ratios at different geomorphological conditions.

section are not considered significant because of the wide valley shape, and the effects of the three dimensional structure will be small. At sand dune, there is a stiff gravel layer beneath a sand layer at the surface. The gravel layer contributes to the smaller amplification at sand dune. At back marsh, the collapsed ratio increases with the increase in the thickness of surface deposits. The collapsed ratio which should be strongly related to the site amplification can be accurately estimated from the geomorphological land classification together with the thickness of surface deposits. The results suggest that it is important for more accurate microzoning to consider the regional characteristics of soil conditions and that the damage data can be the basic data for verification and revision of the site amplification evaluation techniques.

\section{Concluding remarks}

Many techniques for seismic zoning have been proposed. To verify the results and to 

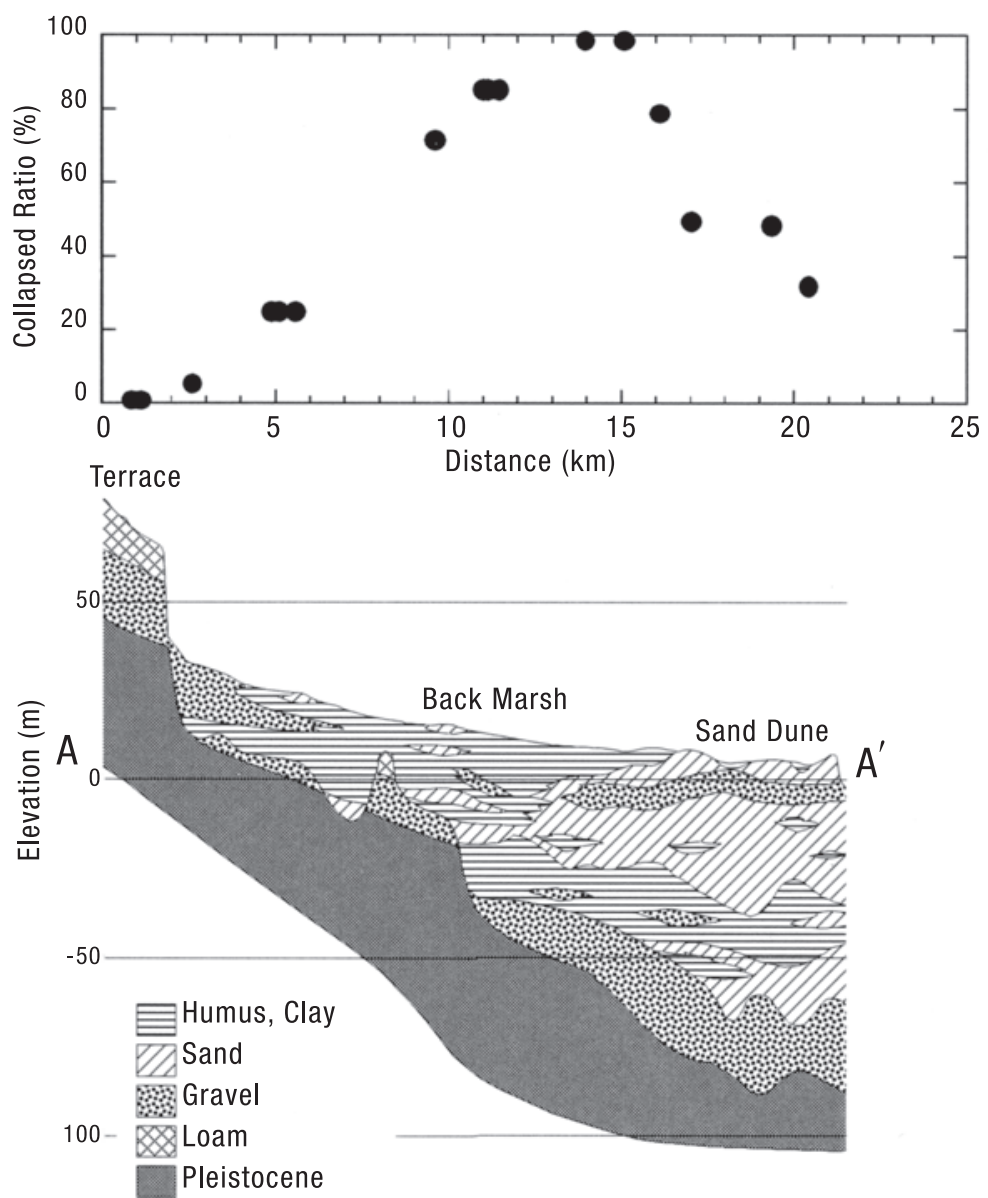

Fig. 10. Soil profile along the Sagami River (Kanagawa Prefecture, 1985) and collapsed ratios.

improve the techniques, the damage data of past destructive earthquakes are still an important key reference. In this paper, as an example, the damage data of the 1923 Kanto, Japan earthquake in the epicentral region are collected and compiled to produce the most reliable and detailed damage map. The damage map is compared with the results from the existing damage assessment and is used to discuss revision of the site amplification evaluation. Through the case study of the Kanto earthquake, it was reconfirmed that digging, collection and compilation of the damage data of past destructive earthquakes should be continuously promoted for improvement of seismic microzoning.

\section{Acknowledgements}

The author wishes to express his sincere thanks to Hiroshi Shinbo and Kazuo Fujimoto for preparation of the figures.

\section{REFERENCES}

Agricultural Association of KanAGAWA PREFECTURE (1925): Report on reconstruction of houses damaged by the Kanto earthquake, J. Agric. Ass. Kanagawa Prefecture, 196, 1-26 (in Japanese).

CommitTeE For Publication of Yokosuka City EARTHQUAKE DISASTER REPORT (1932): Yokosuka City 
Earthquake Disaster Report (in Japanese).

GeOlogical SuRVEY OF JAPAN (1925a): Report on the Damage Investigation of the 1923 Kanto Earthquake, vol. 1 (in Japanese).

GEOLOGICAL SURVEY OF JAPAN (1925b): Report on the Damage Investigation of the 1923 Kanto Earthquake, vol. 2 (in Japanese).

IMAMURA, A. (1913): Seismic intensity distributions in Tokyo and Osaka, Rep. Imp. Earthquake Invest. Comm., 77, 17-42 (in Japanese).

INOUE, K. (1925): Preliminary note on the physiographical investigation of the Great Earthquake of S.E. Japan, Rep. Imp. Earthquake Invest. Comm., 100 (B), 95-96 (in Japanese).

KANAGAWA PREFECTURE (1927): Report of the Earthquake Disaster in Kanagawa Prefecture (in Japanese).

KANAGAWA PREFECTURE (1985): Earthquake Disaster Assessment of Kanagawa Prefecture (Volume of Geological and Soil Data) (in Japanese).

KANAGAWA PREFECTURE (1999): Report on Earthquake Disaster Assessment of Kanagawa Prefecture (in Japanese).

MatsouKA, M. and S. MidoriKaWA (1995): GIS-based integrated seismic hazard mapping for a large metropolitan area, in Proceedings of the Fifth International Conference on Seismic Zonation, 2, 1334-1341.

MatsuZAWA, T. (1925): Intensity distribution deduced from the damages on wooden buildings, Rep. Imp. Earthquake Invest. Comm., 100 (A), 163-260 (in Japanese).

MINISTRY OF DOMESTIC AFFAIRS (1926): Report on the Great Kanto Earthquake Disaster (in Japanese).

MOROI, T. and M. TAKEMURA (2001): Comparison of damage data for the 1923 Kanto earthquake and strong ground motion in Tokyo, J. Struct. Constr. Eng, AIJ, 540, 65-72 (in Japanese with English abstract).

NisHisAKA, M. (1924): Memorandum on Earthquake Disaster in Kanagawa Prefecture (in Japanese).

NoBATA, A. and S. MidorIKAWA (2002): Near-field ground motion intensity estimated from damage distribution of wooden houses during the 1948 Fukui earthquake, J. Struct. Constr. Eng., AIJ, 553, 27-32 (in Japanese with English abstract).

RISK MANAGEMENT SOLUTIONS (1995): What if the 1923 Earthquake Strikes Again? A Five-Prefecture Tokyo Region Scenario.

SHINBO, H. and S. MIDORIKAWA (2001): Damage distribution of wooden houses in Kanagawa Prefecture during the Kanto earthquake and its relation with surface geology, J. Soc. Saf. Sci., 3, 109-116 (in Japanese with English abstract).

TAKAhAma, T., S.Midorikawa, H. Shinbo and S. ABE (2001): Damage distribution of wooden houses in Yokohama City during the 1923 Kanto earthquake, in Proceedings of the 26th JSCE Earthquake Engineering Symposium, 1, 105-108 (in Japanese).

TAKEMURA, M. and T. Moroi (2001a): Comprehensive list of the regional damage data sets for the 1923 Kanto earthquake, J. Seismol. Soc. Jpn., 53, 285-302 (in Japanese with English abstract).

TAKemura, M. and T. MoroI (2001b): Detailed seismic intensity distribution due to the 1923 Kanto earthquake based on the data of the report by the Geological Survey of Japan. Part 1. Chiba Prefecture, J. Jpn. Ass. Earthquake Eng. 1, 1-26 (in Japanese with English abstract).

TAKEMURA, M. and T. MOROI (2001c): Damage and strong ground motion distribution from the 1923 Kanto earthquake. Part 3. Saitama Prefecture, Abstracts, 2001 Japan Earth and Planetary Science Joint Meeting, Sp-P009 (in Japanese with English abstract).

TAKEMURA, M. and T. MOROI (2001d): Damage and strong ground motion distribution from the 1923 Kanto Earthquake. Part 4. Ibaragi Prefecture, Programme and Abstracts, The Seismological Society of Japan, 2001, Fall Meeting, A51 (in Japanese).

TECHNICAL COMMITTEE FOR EARTHQUAKE GEOTECHNICAL ENGINEERING, TC4, ISSMGE (1999): Manual for Zonation on Seismic Geotechnical Hazards (Revised Version), The Japanese Geotechnical Society. 